\title{
An investigation of gravity wave activity in the low-latitude upper mesosphere: Propagation direction and wind filtering
}

\author{
A. F. Medeiros \\ Departamento de Física, Universidade Federal de Campina Grande, Campina Grande, Brazil \\ M. J. Taylor \\ Space Dynamics Laboratory and Physics Department, Utah State University, Logan, Utah, USA
}

H. Takahashi, P. P. Batista, and D. Gobbi

Instituto Nacional de Pesquisas Espaciais, São José dos Campos, Brazil

Received 30 May 2002; revised 8 November 2002; accepted 19 February 2003; published 18 July 2003.

[1] An all-sky charge-coupled device imager capable of measuring wave structure in the $\mathrm{OH}, \mathrm{O}_{2}$, and $\mathrm{O} \mathrm{I}(557.7 \mathrm{~nm})$ airglow emissions was operated at Cachoeira Paulista, Brazil $\left(23^{\circ} \mathrm{S}, 45^{\circ} \mathrm{W}\right)$, for 2 years in collaboration with Utah State University, Logan. The dominant quasi-monochromatic gravity wave components investigated over a $\sim 1$ year period (September 1998 to October 1999) have been extracted, and their seasonal variations have been measured. A total of 283 wave events were measured, exhibiting horizontal wavelengths from 5 to $60 \mathrm{~km}$, observed periods from 5 to $35 \mathrm{~min}$, and horizontal phase speeds of up to $\sim 80 \mathrm{~m} \mathrm{~s}^{-1}$. The large-scale "band" wave patterns (horizontal wavelength between 10 and $60 \mathrm{~km}$ ) exhibited a clear seasonal dependence on the horizontal propagation direction, propagating toward the southeast during the summer months and toward the northwest during the winter. The direction of propagation was observed to change abruptly around the equinox period in mid March and at the end of September. Using a numerical simulation of gravity wave propagation in a seasonally variable climatological wind field, we have determined that the observed anisotropy in the wave propagation directions can be attributed to a strong filtering of the waves in the middle atmosphere by stratospheric winds. INDEX TERMS: 0310 Atmospheric Composition and Structure: Airglow and aurora; 3332 Meteorology and Atmospheric Dynamics: Mesospheric dynamics; 3360 Meteorology and Atmospheric Dynamics: Remote sensing; KEYWORDS: airglow, winds, gravity waves, wind filtering, imager

Citation: Medeiros, A. F., M. J. Taylor, H. Takahashi, P. P. Batista, and D. Gobbi, An investigation of gravity wave activity in the low-latitude upper mesosphere: Propagation direction and wind filtering, J. Geophys. Res., 108(D14), 4411, doi:10.1029/2002JD002593, 2003.

\section{Introduction}

[2] Most of the nightglow image measurements reported in the literature concern short-period ( $<1$ hour) wave-like oscillations evident in the visible and near-infrared airglow layers. These oscillations have been classified into two distinct categories termed "bands" and "ripples," respectively. Bands are extensive, long-lasting wave patterns exhibiting horizontal wavelengths of several tens of kilometers and horizontal phase velocities up to $100 \mathrm{~m} \mathrm{~s}^{-1}$. These patterns have been attributed to freely propagating or ducted short-period gravity waves [Walterscheid et al., 1999; Isler et al., 1997; Taylor et al., 1987]. Ripples are short-lived (<45 min) small-scale wave patterns of restricted spatial extent [Peterson, 1979] and are thought to be generated in situ by localized shear or convective-type instabilities in the total wind field [e.g., Taylor and Hapgood, 1990; Hecht et al., 1995]. Figure 1 shows these two types of wave pattern observed from Cachoeira Paulista during this period. Using all-sky image data obtained by the same imaging system from Maui, Hawaii $\left(20^{\circ} \mathrm{N}\right)$, Isler et al. [1997] determined that Doppler ducting may explain a significant fraction $(70 \%)$ of the waves seen in all-sky images. Nakamura et al. [1999] analyzed 18 months of data and extracted dominant gravity wave components in the $\mathrm{OH}$ images and investigated seasonal variation of the characteristics of the waves. Walterscheid et al. [1999] analyzing 9 months of airglow image observations of atmospheric gravity waves proposed that many waves were thermally ducted. Hecht et al. [2001] analyzing 15 months of observations suggested that the waves originated no more than a few thousand kilometers from the observation site and that winds could form the upper evanescent region needed for the ducting of some waves.

[3] Taylor et al. [1993], from observations of $\mathrm{OH}$ airglow images obtained in the summer months of May, June, and 


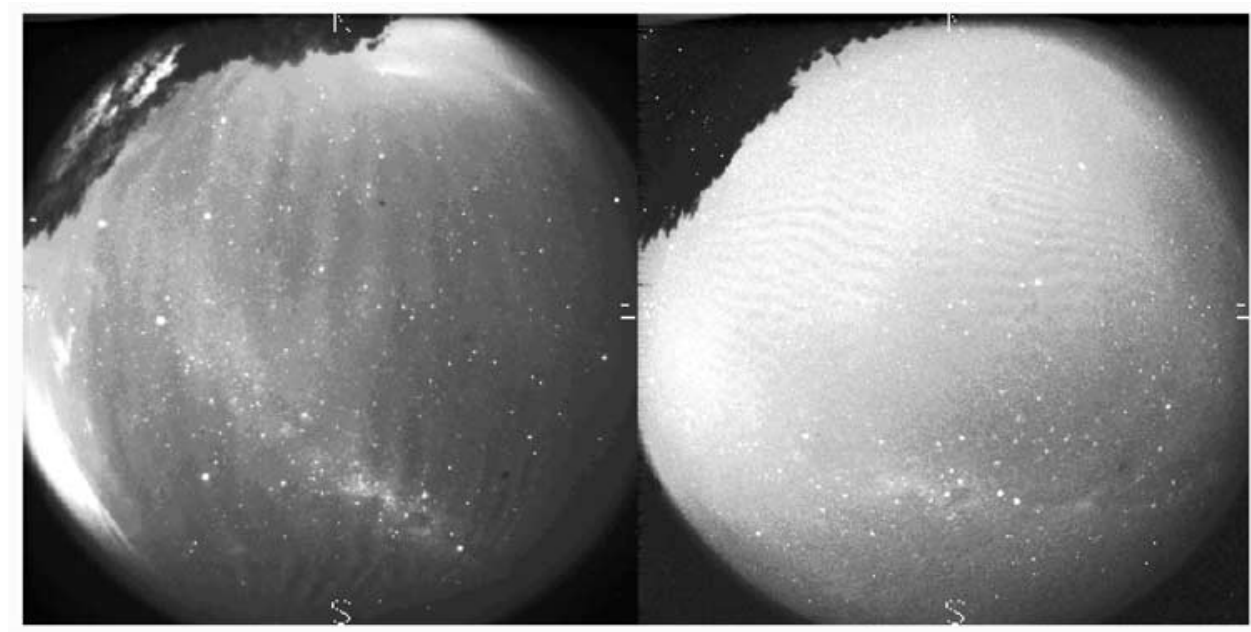

Figure 1. Observed airglow images of the (right) O I 5577 emission showing ripples on the night of 16 May 1999 at 2342 UT and (left) OH showing bands on the night of 11 April 1999 at 0429 UT at Cachoeira Paulista $\left(23^{\circ} \mathrm{S}, 45^{\circ} \mathrm{W}\right)$.

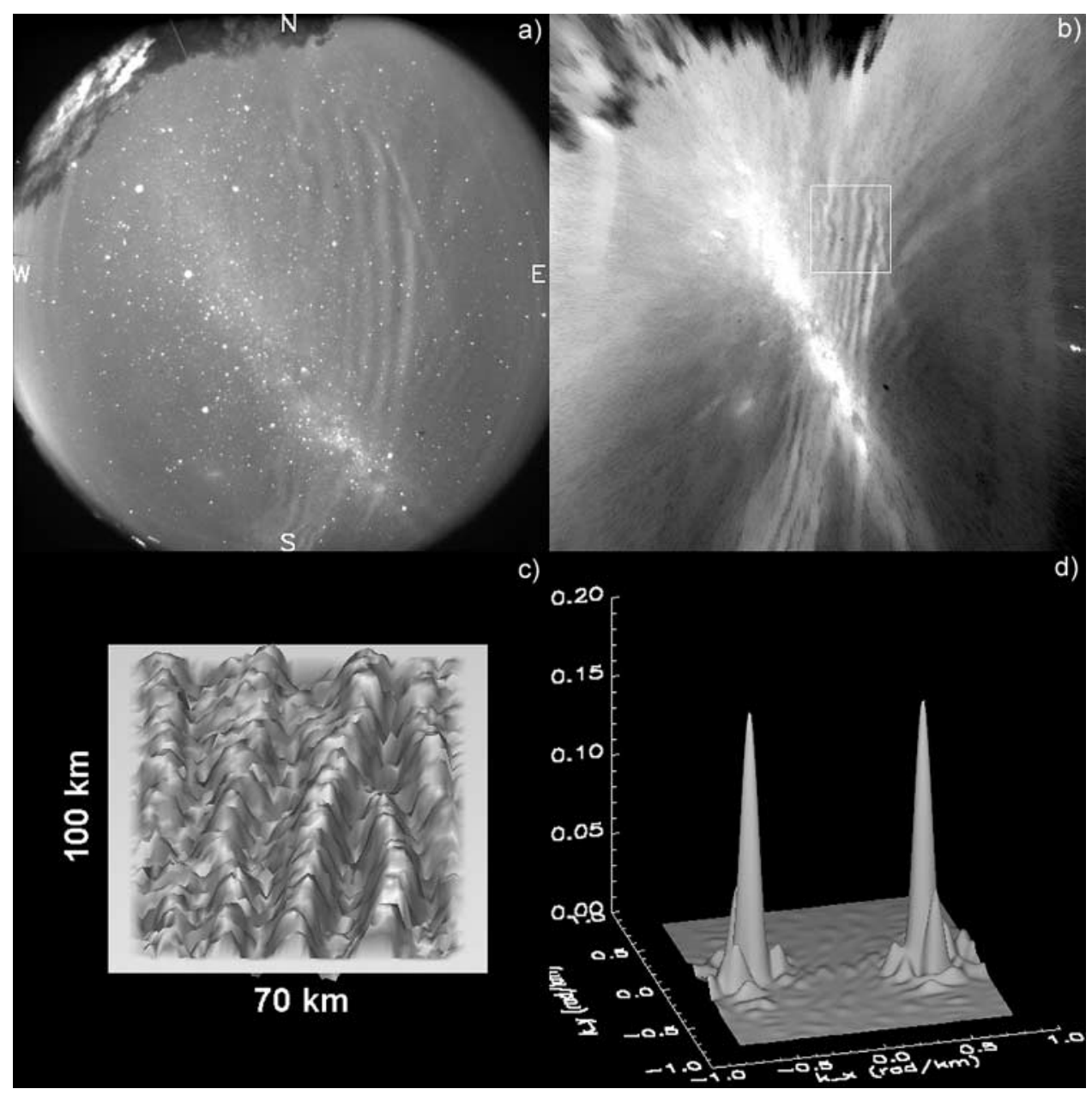

Figure 2. (a) A $512 \times 512$ resolution all-sky charge-coupled device (CCD) raw image showing a gravity wave event in the OH airglow emission observed on the night of 19 January 1999 at 0139 UT, (b) the same but unwarped image, (c) three-dimensional image of a selected event shown in Figure $2 \mathrm{~b}$ as a rectangle area, and (d) power spectra of the selected event in arbitrary units and $x$ and $y$ axis in wave number $(2 \pi / \lambda)$ in $\mathrm{rad}^{-1}$. 


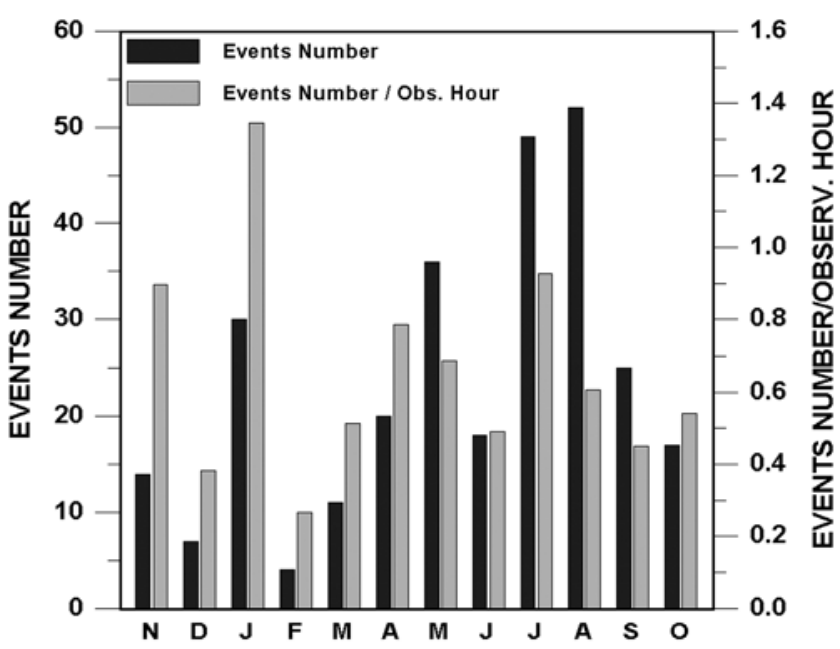

Figure 3. Frequency of occurrence of wave activity (bands and ripples).

July in Colorado $\left(40^{\circ} \mathrm{N}\right)$, observed a tendency for shortperiod gravity waves ( $<1$ hour) to propagate in the northward direction. They suggested that this preferential direction of the gravity waves could be a result of blocking at a critical layer produced by the interaction of the upward propagating waves with the horizontal background flow. The method- ology they used was to construct diagrams based in wind models and the critical layer theory to show regions where upward gravity waves were forbidden to propagate.

[4] This paper describes new image measurements of short-period waves observed from a low-latitude site in the Southern Hemisphere. To investigate the gravity wave morphology, a series of measurements were carried out over 12 consecutive months (October 1998 to September 1999). The observations revealed similar spatial and temporal variations for the wave displays observed during each month, but a distinct tendency toward preferential directions of motion was noted, mainly for summer and winter, and the same methodology used by Taylor et al. [1993] is used to explain the observations.

\section{Instrumentation and Methodology}

[5] Routine airglow observations have been carried out at Cachoeira Paulista $(\mathrm{CP}),\left(23^{\circ} \mathrm{S}, 45^{\circ} \mathrm{W}\right)$, using an all-sky imaging system. This is a collaborative program between the Instituto Nacional de Pesquisas Espaciais, Brazil, and the Space Dynamics Laboratory, Utah State University (M. J. Taylor). The charge-coupled device (CCD) imager consists of a large area $\left(6.45 \mathrm{~cm}^{2}\right)$, high-resolution, $1024 \times 1024$ back-illuminated array with a pixel size of 14 bits. The high quantum efficiency ( $\sim 80 \%$ at visible wavelengths), low dark current ( 0.5 electrons ${ }^{-1}$ pixel $\left.^{-1} \mathrm{~s}\right)$, low readout noise
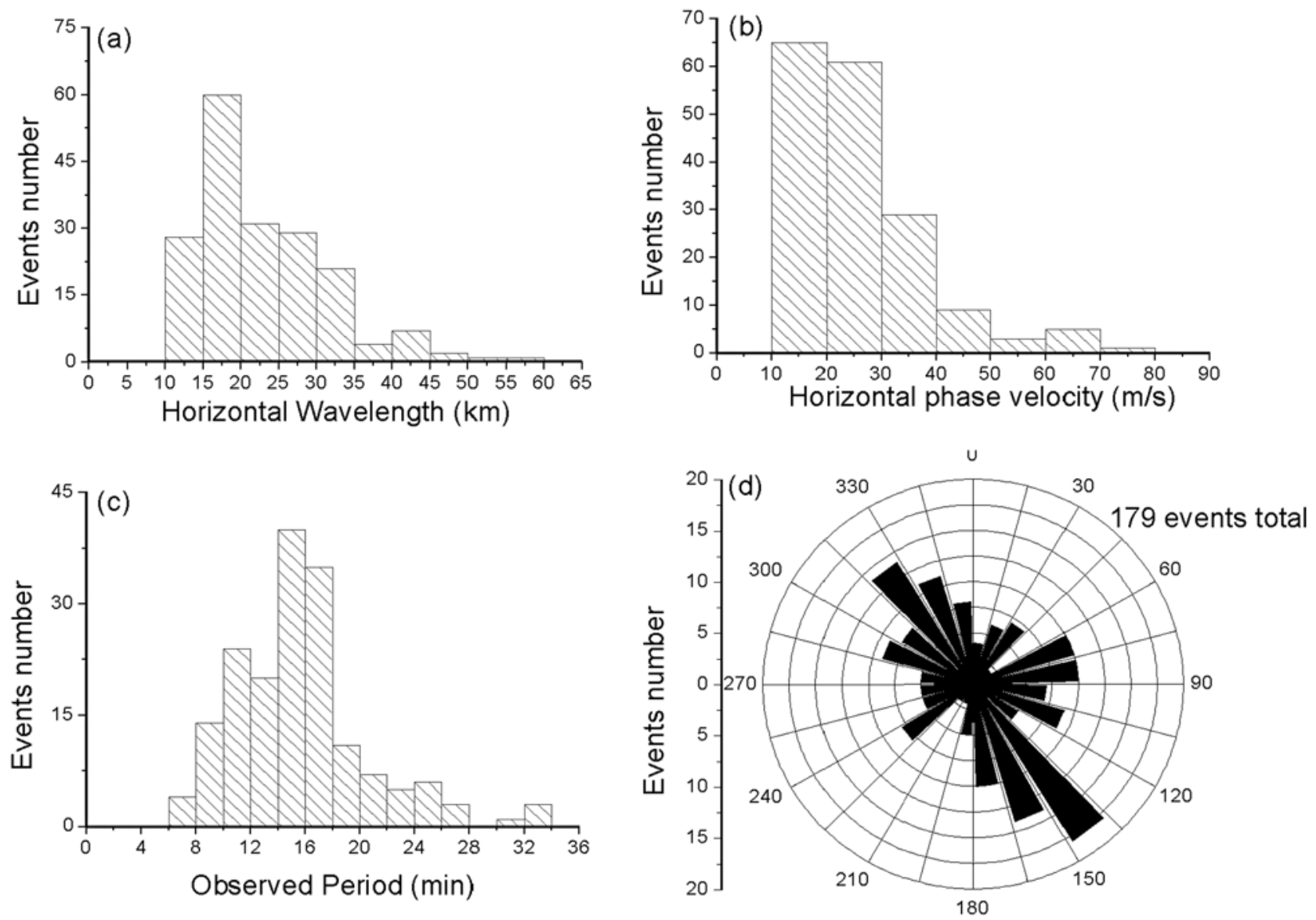

Figure 4. (a) Frequency of occurrence of the horizontal wavelength, with $5 \mathrm{~km}$ interval, (b) the same for horizontal phase velocity, with $10 \mathrm{~m} \mathrm{~s}^{-1}$ interval, (c) same as Figure 4a but for observed period, with 2 min interval, (d) same as Figure 4 a but for propagation direction, with $15^{\circ}$ interval. 


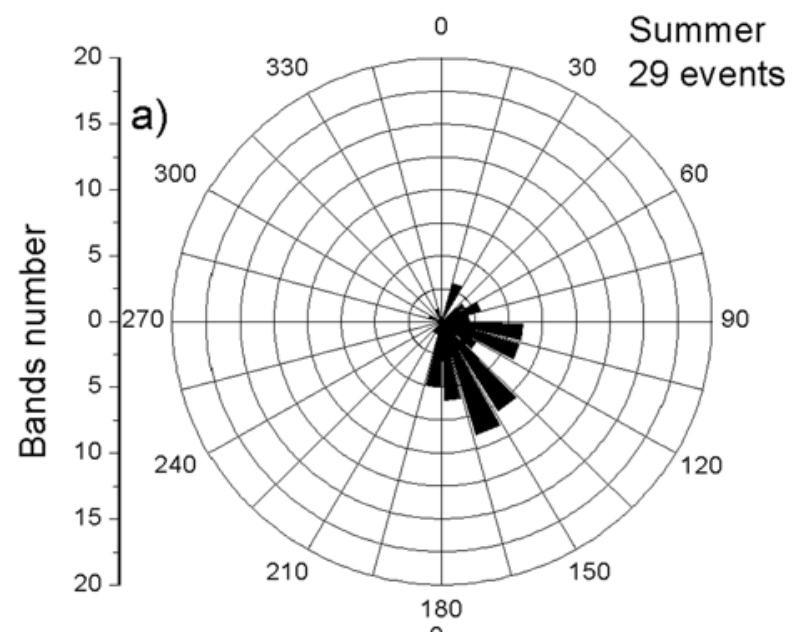

Summer

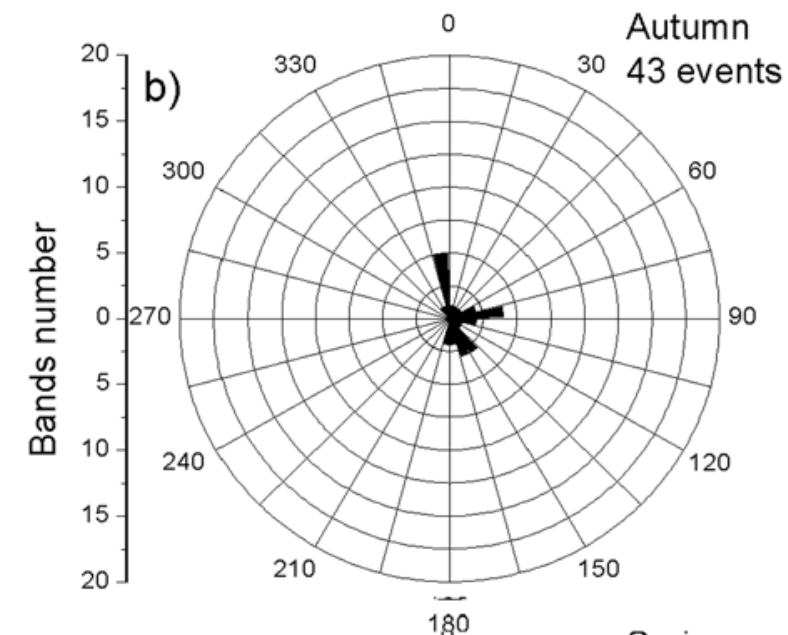

Autumn
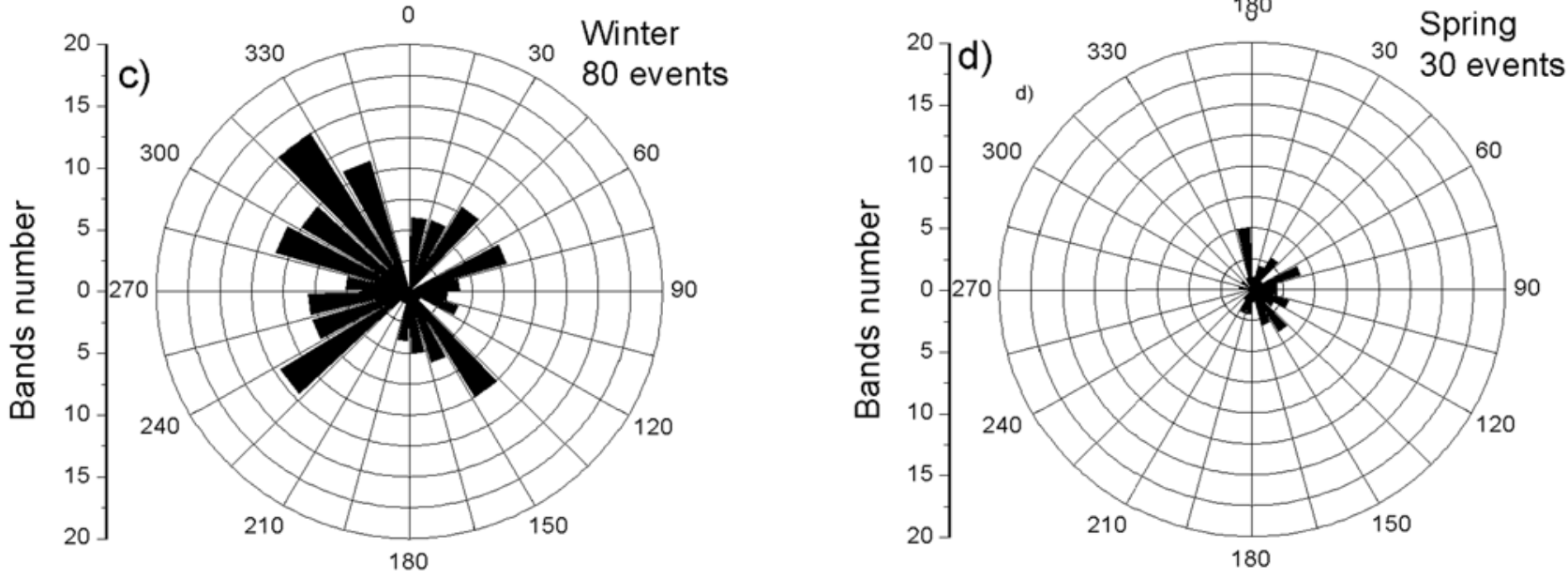

Figure 5. Propagation direction distribution for bands in (a) summer, (b) autumn, (c) winter, and (d) spring.

(15 electrons rms), and high linearity $(0.05 \%)$ of this device made it possible to achieve quantitative measurements of the airglow emissions. The camera uses a fast (f/4) all-sky telecentric lens system that enables high signal-to-noise (20:1) images of wave structure to be obtained with time integration of typically $15 \mathrm{~s}$ for the near-infrared $\mathrm{OH}$ emission (715-930 nm passband) and $90 \mathrm{~s}$ for the $\mathrm{O} I$ $(557.7 \mathrm{~nm}), \mathrm{O}_{2}$, and $\mathrm{O} \mathrm{I}(630.0 \mathrm{~nm})$ emissions. The image was binned on chip down to $512 \times 512$ resolution to enhance the signal-to-noise ratio. Figure 2 a shows a $512 \times 512$ resolution all-sky CCD raw image showing a gravity wave event in the $\mathrm{OH}$ airglow emission. The same, but unwarped, image with the selected event is shown in Figure 2b. Figure $2 \mathrm{c}$ shows a three-dimensional (3-D) image of the selected event, and Figure 2d shows its 2-D power spectra.

[6] For the wide-angle all-sky image data, spatial calibration is essential. We can achieve this by using the stars in each image as known reference points in the sky. When an image has been calibrated (Figure 2a), it is beneficial to remove the stars because they cause streaking when an image is projected onto geographic coordinates. After processing the all-sky images, it is now possible to determine the horizontal wave parameters directly with standard 2-D fast Fourier transform (FFT) analysis. The advantage of this method is that measurements of all of the monochromatic features present in the data are now possible. We can investigate gravity wave content in any part of the image by isolating the region of interest (Figure 2b), taking the 2-D FFT of the selected region and investigating peaks in the frequency spectrum. Another way to show these events is to exhibit it in three dimensions. Figure $2 \mathrm{c}$ shows the event, and Figure $2 \mathrm{~d}$ shows its respective spectrum in three dimensions. Owing to the symmetry of the FFT of real data, two mirrorimage peaks in the power spectrum are evident in the second quadrant with $k_{x}=-0.46 \mathrm{rad} \mathrm{km}^{-1}$ and $k_{y}=0.039 \mathrm{rad} \mathrm{km}^{-1}$ and in the fourth quadrant with $k_{x}=0.46 \mathrm{rad} \mathrm{km}^{-1}$ and $k_{y}=$ $-0.039 \mathrm{rad} \mathrm{km}^{-1}$. We can determine the horizontal wavelength of the wave by computing the inverse of the distance of the peak from the origin, and this was found to be $13.4 \mathrm{~km}$. The determination of the period (and hence phase speed) of the waves present in these data involves taking the onedimensional (1-D) FFT in the time of the complex 2-D FFT in space. The peaks in the 1-D FFT correspond to the wave frequencies present in the data. The $\mathrm{O}_{2}$ images were not used in the 1-D spectral analysis, because the temporal resolution was larger than for the other emissions. However, they were used for the study of the other wave parameters.

\section{Results}

[7] Measurements were taken during October 1998 to September 1999. The number of observed events and the 

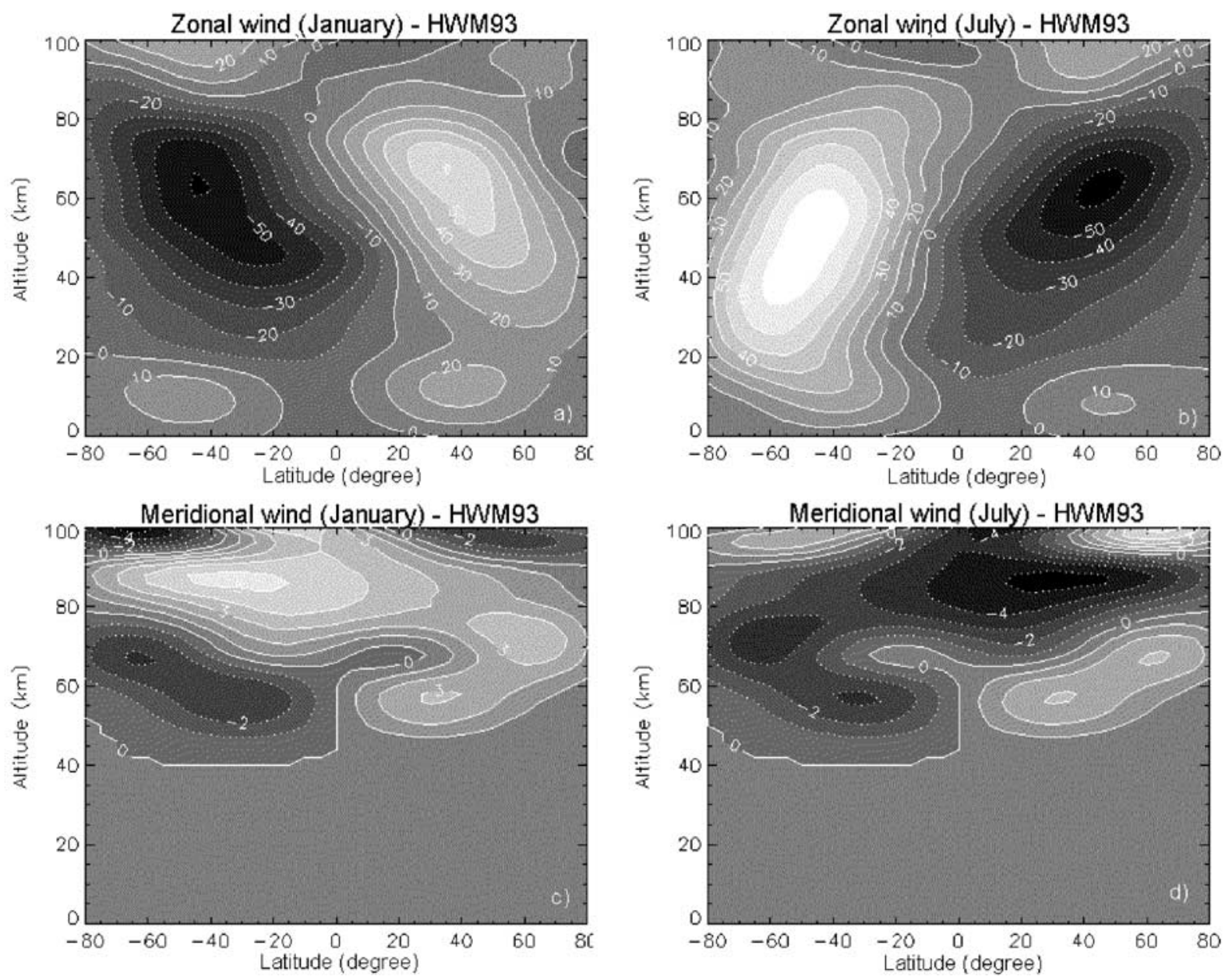

Figure 6. (top) Zonal and (bottom) meridional winds for the months of (a) January (zonal), (b) July (zonal), (c) January (meridional), and (d) July (meridional) from the HWM93 model.

number of events per hour of observations are depicted in Figure 3. Despite restrictions imposed by tropospheric clouds, $\sim 433$ hours of useful data were recorded on 69 nights, in which 283 wave events were observed. The mean rate of the events was 0.7 events hour ${ }^{-1}$ with higher mean rate in summer and winter months and lower mean rate in equinoctial months.

[8] After the general comparison of the bands and ripples we analyzed wave parameters (wavelength, period, phase velocity, and propagation direction) for each season. Figure 4 shows the wave parameters for the band type. Figure 4a shows the distribution of horizontal wavelength of bands as a function of their frequency of occurrence. The data were binned into histograms of $5 \mathrm{~km}$ width. This shows the most frequently observed horizontal scale sizes. The band distribution exhibited a significantly broader range of horizontal wavelengths extending from $\sim 10$ to $60 \mathrm{~km}$, and $85 \%$ of all bands had wavelengths $>15 \mathrm{~km}$. The average band wavelength was $22.9 \mathrm{~km}$. The resulting distribution of observed wave periods (binned with 2 min intervals) is given in Figure $4 \mathrm{~b}$. The distribution of the periods of the bands shows a clear tendency toward longer wave periods (with $97 \%$ of bands exhibiting periods $>8 \mathrm{~min}$ ). The bands exhibited an average wave period of $15.62 \mathrm{~min}$. Figure $4 \mathrm{c}$ shows the distribution of wave phase speeds plotted at $10 \mathrm{~m} \mathrm{~s}^{-1}$ intervals. The bands measurements range from 10 to $80 \mathrm{~m} \mathrm{~s}^{-1}$ and exhibit an average value of $26.1 \mathrm{~m} \mathrm{~s}^{-1}$. There is a clear tendency for many of the waves to exhibit phase speed in the $10-40 \mathrm{~m} \mathrm{~s}^{-1}$ range. The wave propagation directions binned over $15^{\circ}$ intervals are plotted in Figure 4d. The distribution of bands is highly anisotropic, exhibiting two directions of preference: southeast (azimuth range $90^{\circ}-$ $180^{\circ}$ ) and northwest (azimuth range $270^{\circ}-360^{\circ}$ ).

[9] In order to examine the seasonal tendency of the wave parameters, the data were grouped into four seasons: summer (November, December, January, and February), autumn (March and April), winter (May, June, July, and August), and spring (September and October). For wavelengths, periods, and phase velocities we found no clear seasonal variation, neither for ripples nor bands. However, the bands showed a seasonal variation for propagation direction. Figure 5 shows a clear preference for propagation direction of the bands in summer and winter. In summer the preferential propagation direction is toward southeast. In winter the preferential propagation direction is toward northwest. In the other seasons no clear preferential propagation directions were observed. The ripples did not present seasonal variations in propagation direction. 


\section{Discussion}

[10] The anisotropy detected in propagation direction of the bands, mainly for summer and winter could be due to the presence of a critical level. Gravity waves propagating upward from the lower atmosphere are absorbed into the mean flow as they approach a critical layer where the intrinsic frequency of the wave is Doppler shifted to zero. This situation may occur at any height when the local horizontal wind speed along the direction of propagation equals the observed horizontal phase speed of the gravity wave. The theory of gravity wave absorption at critical layers is well developed [Booker and Bretherton, 1967; Hines and Reddy, 1967; Hazel, 1967; Jones, 1968; Fritts and Geller, 1976; Fritts, 1979; He et al., 1990, 1991].

[11] At the critical layer height a horizontal surface can be constructed to give a polar plot (a "blocking diagram") showing the range of azimuthal angles and speeds of gravity waves forbidden from further upward propagation [Ryan, 1991; Ryan and Tuan, 1991; Taylor et al., 1993; Zhong et al., 1996; Manson et al., 1999]. Gravity waves with horizontal phase velocity and directions within this region would encounter heavy absorption as they approach to the critical layer. Gravity waves with horizontal phase velocities outside this region would not meet by chance a critical layer and should be observable. The Doppler-shifted frequency, $\Omega$, due to the horizontal wind $V_{0}$ is given by

$$
\Omega=\omega-k_{x} V_{0 x}
$$

where $\omega$ is the source frequency, $k_{x}$, is the magnitude of the horizontal wave vector, and $V_{0 x}$ is component of $V_{0}$ along the wave propagation direction. Equation (1) can be rewritten as

$$
\Omega=\omega\left(1-\frac{V_{0 x}}{v_{x}}\right)
$$

where $v_{x}$ is the observed horizontal phase speed of the wave. Equation (2) can be expressed in terms of the zonal and meridional wind components $\left(V_{z}, V_{m}\right)$ as

$$
\Omega=\omega\left(1-\frac{V_{z} \cos \phi+V_{m} \sin \phi}{v_{x}}\right)
$$

Thus at the critical layer when $V_{0 x}$ tends to $v_{x}$ and $\Omega$ tends to zero, the equation (3) can be written as

$$
v_{x}=V_{z} \cos \phi+V_{m} \sin \phi
$$

Equation (4) can be represented in a polar plot of $v_{x}$ for every azimuth knowing $\left(V_{z}, V_{m}\right)$. This diagram called "blocking diagram" is used to find regions with $\Omega \leq 0$ or the forbidden regions at any height below the peak of the emission layer for each propagation direction $\phi$ and phase speed $v_{x}$.

[12] In the absence of simultaneous wind measurements we used wind profiles taken from horizontal wind model (HWM93) [Hedin et al., 1996]. Figure 6 shows zonal and meridional winds for the months of January and July. For January, two different wind systems for the zonal wind can be noted, one in the lower and other in the middle

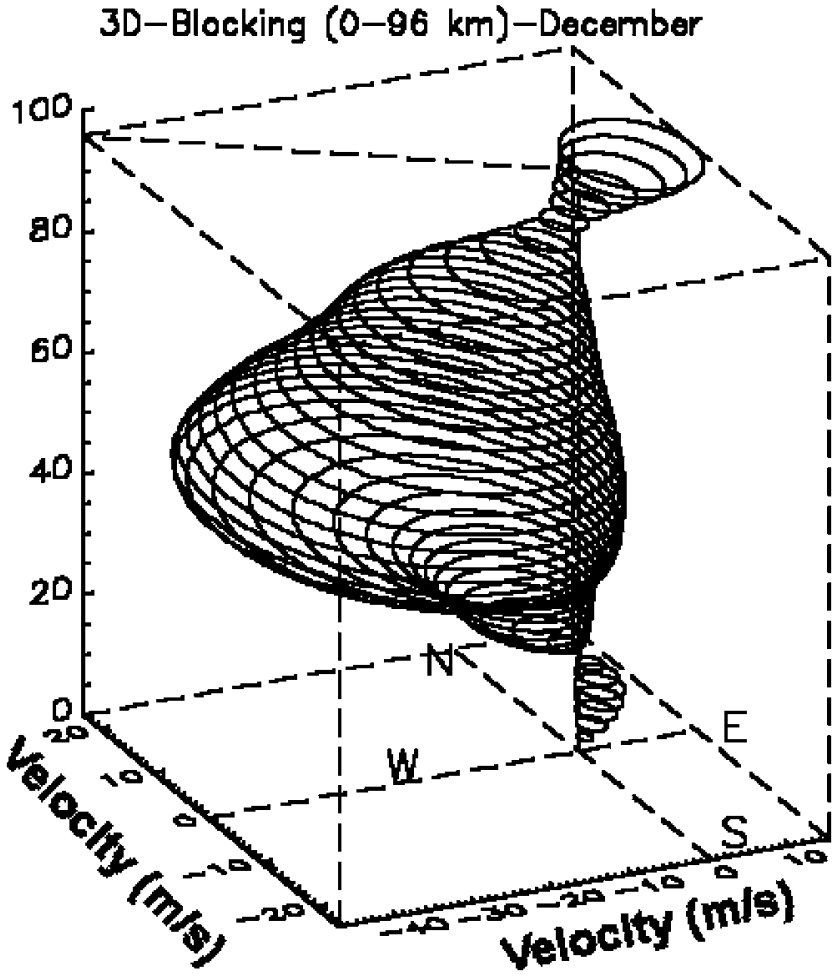

Figure 7. Three-dimensional blocking diagram from 0 to $96 \mathrm{~km}$ for December.

atmosphere. A strong wind blows (between 20 and $90 \mathrm{~km}$ ) to the west in the summer hemisphere and to the east in the winter hemisphere. In July, there is an inversion; the wind blows to the east in the summer hemisphere and blows to the west in the winter hemisphere.

[13] Blocking diagrams were plotted for each month of the year using the wind profiles derived from HWM93 [Hedin et al., 1996] for Cachoeira Paulista. Nearly 90\% of the bands were out of the forbidden region. The waves that fall in this region may be ducted waves that propagated from a large horizontal distance [Isler et al., 1997] or Doppler shifted outside of the forbidden region. This and the lifetime of some critical levels allow waves to survive the critical layer and reach higher altitudes [Zhong et al., 1996]. Figure 7 shows a 3-D blocking diagram from 0 to $96 \mathrm{~km}$ for December.

[14] Since the wind model shows a clear seasonal variation from summer to winter, we calculated the blocking diagram for the four seasons separately. Figure 8 shows blocking diagrams superimposed with the waves observed for each season of the year for the $\mathrm{OH}$ emission. Figure 8 shows the top view of Figure 7 for each season. Most of the waves are out of the forbidden region. The results agree with the anisotropy detected in the bands. This fact suggests that wave filtering by winds can play an important role in the seasonal variation of the waves over Cachoeira Paulista.

[15] The comparison of the image measurements with model predictions shows an almost complete agreement between the prediction of the forbidden regions and the observed propagation directions of the waves. The anisotropy observed in the propagation direction of waves could be due to a nonuniform distribution of sources of gravity 

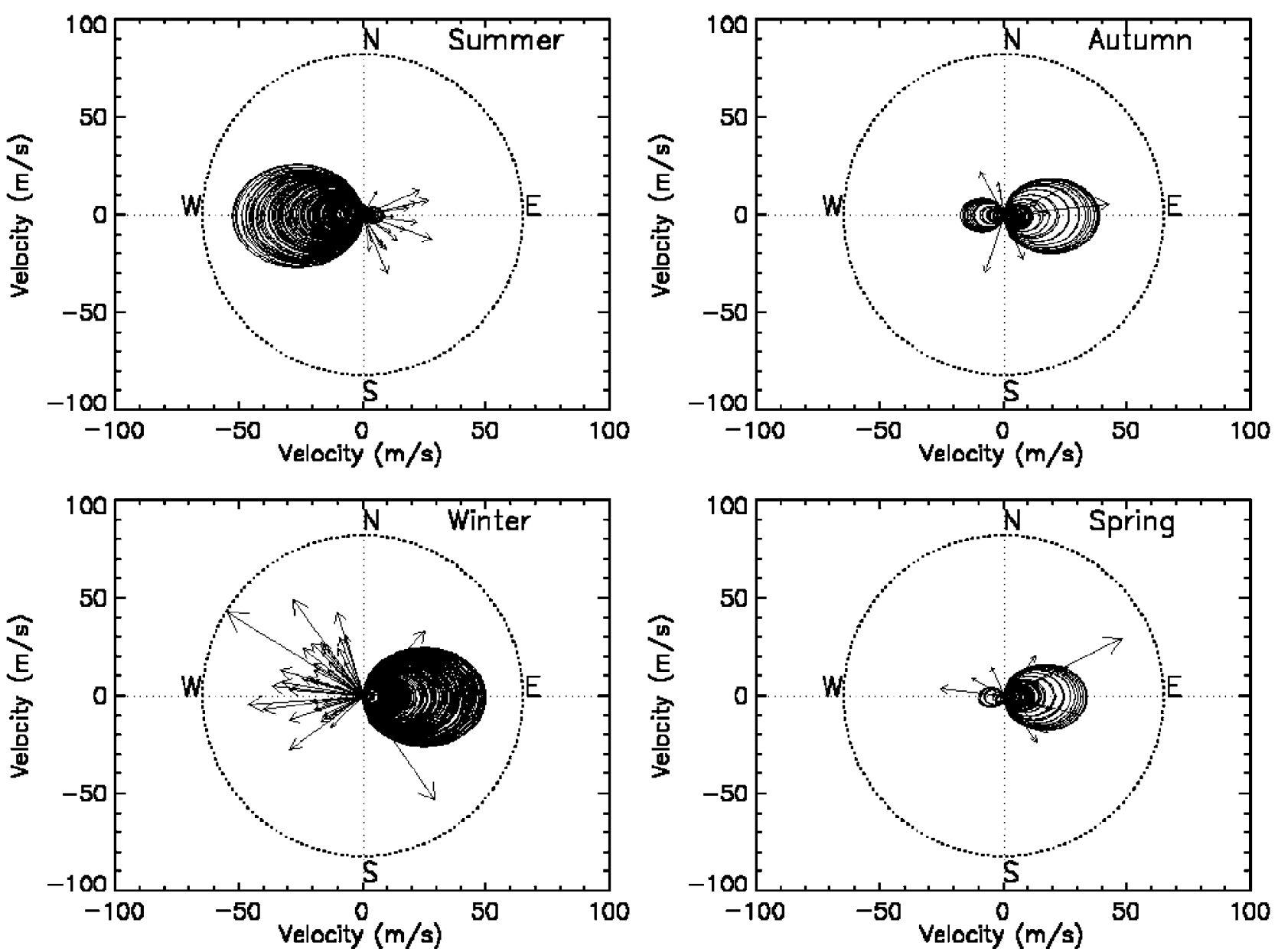

Figure 8. Blocking diagram for each season at the $\mathrm{OH}$ layer height $(86 \mathrm{~km})$. The arrows show the magnitudes and directions of the phase velocity of the waves during each season.

waves. This requires that the wave sources were located mainly to the northwest in summer and southeast in the winter. The sources of the waves observed during this period are under investigation. Thunderstorm activity has been identified as a source of short-period gravity waves on at least one prior occasion by Taylor and Hapgood [1988], Walterscheid et al. [1999], and Hecht et al. [2001]. Lightning imaging sensor (LIS) data http://thunder.nsstc.nasa. gov/data/query/distributions.html) shows that most of the lightning occurrence over South America in summer extends approximately in a line from northern Argentina almost to the Brazilian northeast, with a conspicuous concentration over central Brazil, and that in winter, in contrast to summer, the lightning is concentrated south of Cachoeira Paulista, mainly over the sea, and there is no convection to the north in the central region of Brazil. The LIS is a space-based instrument used to detect the distribution and variability of total lightning (cloud-to-cloud, intracloud, and cloud-toground lightning) that occurs in the tropical regions of the globe. The LIS is a scientific instrument aboard the Tropical Rainfall Measuring Mission observatory. While the distribution of the wave sources during this period was not uniform, it is highly improbable that it would have given rise to the observed set of wave motions. As the wind in the middle atmosphere (see Figure 6) can be large compared with the apparent phase velocity of the waves, it is most likely that the anisotropy in the data resulted from directional filtering of an ensemble of wave motions.

[16] The results of this study are quite remarkable when it is recalled that the blocking diagrams were developed using climatological data that provide only an estimate of the wave filtering to be expected at Cachoeira Paulista. Ideally, for this type of investigation, simultaneous wind profile measurements should be made in the vicinity of the airglow observations. However, more measurements are needed before any conclusion can be drawn on this point. In particular, new investigations, which are now being carried out using measurements taken at another site in the Brazilian equatorial region, should provide a further important test of the present theory.

\section{Conclusion}

[17] This work is a result of experimental observations of gravity waves by airglow imaging carried out at Cachoeira Paulista $\left(23^{\circ} \mathrm{S}, 45^{\circ} \mathrm{W}\right)$ in the period from October 1998 to September 1999. A total of the 69 nights corresponding to 433 hours of observations were analyzed. In this period, 283 wave events were detected in the $\mathrm{OH}, \mathrm{O}_{2}$ and $\mathrm{O}$ I 5577 images. The direction of wave propagation is significantly 
anisotropic, mainly southeast during summer and northwest during the winter. The critical layer theory for gravity wave filtering has been applied to an extended set of airglow measurements to study the effects of middle atmospheric winds on the propagation of short-period gravity waves. All-sky images of the airglow emissions are well suited to this research, as they provide precise information on the directions of phase propagation and the apparent speeds of the waves reaching the upper atmosphere. The measurements reported here show almost total agreement between the observed and permitted wave propagation directions and speeds. This result indicates that the anisotropy of propagation direction was almost certainly due wave filtering by stratospheric winds in agreement with the findings of Taylor et al. [1993].

\section{References}

Booker, J. R., and F. P. Bretherton, The critical layer for internal gravity waves in a shear flow, J. Fluid Mech., 23, 513-520, 1967.

Fritts, D. C., The excitation of radiating waves and Kelvin-Helmholtz instabilities by wave-critical level interaction, J. Atmos. Sci., 36, 397-413, 1979.

Fritts, D. C., and M. A. Geller, Viscous stabilization of gravity wave critical level flows, J. Atmos. Sci., 33, 2276-2293, 1976.

Hazel, P., The effect of viscosity and heat conduction on internal gravity waves at a critical level, J. Fluid Mech., 30, 775-786, 1967.

He, F., T. F. Tuan, R. Picard, and J. Isler, Optical model analysis of gravitywave reflections from critical layers, Eos Trans. AGU, 71(43), Fall Meet. Suppl., 1495-1496, 1990.

He, F., T. F. Tuan, R. Picard, and J. Isler, Modeling of optical model treatment of gravity wave-critical layer interactions, Eos Trans. $A G U$, 72(17), Spring Meet. Suppl., 208, 1991.

Hecht, J. H., S. K. R. Howat, R. L. Waltersheid, and J. R. Isler, Observations of spectra of intensity fluctuations of the $\mathrm{OH}$ Meinel nightglow during ALOHA-93, Geophys. Res. Lett., 22, 2873-2876, 1995.

Hecht, J. H., R. L. Walterscheid, M. P. Hickey, and S. J. Franke, Climatology and modeling of quasi-monochromatic atmospheric gravity waves observed over Urbana Illinois, J. Geophys. Res., 106, 5181-5191, 2001.

Hedin, A. E., et al., Empirical wind model for the upper, middle and lower atmosphere, J. Atmos. Terr. Phys., 58, 1421-1434, 1996.

Hines, C. O., and C. A. Reddy, On the propagation of atmospheric gravity waves through regions of wind shear, J. Geophys. Res., 72, 1015-1034, 1967.

Isler, J. R., M. J. Taylor, and D. J. Fritts, Observational evidence of wave ducting and evanescence in the mesosphere, J. Geophys. Res., 102, 26,301-26,313, 1997.
Jones, W. L., Reflexion and stability of waves in stably stratified fluids with shear flow: A numerical study, J. Fluid Mech., 34, 609-619, 1968.

Manson, A. H., C. E. Meek, C. Hall, W. K. Hocking, J. MacDougall, S. Franke, K. Igarashi, D. Riggin, D. C. Fritts, and R. A. Vincent, Gravity wave spectra, directions and wave interactions: Global MLT-MFR network, Earth Planets Space, 51, 543-562, 1999.

Nakamura, T., A. Higashikawa, T. Tsuda, and Y. Matsushita, Seasonal variations of gravity wave structures in $\mathrm{OH}$ airglow with a CCD imager at Shigaraki, Earth Planets Space, 51, 897-906, 1999.

Peterson, A. W., Airglow events visible to the naked eye, Appl. Opt., 22, 3390-3393, 1979.

Ryan, E. H., Critical layer directional filtering of atmospheric gravity waves: A comparison of airglow and wind profile model, M.S. thesis, Univ. of Cincinnati, Cincinnati, Ohio, 1991.

Ryan, E. H., and T. F. Tuan, Gravity waves blocking by critical layers, paper presented at Middle Atmosphere Periodic Structure and Associated Radiance (MAPSTAR) Meeting, Air Force Geophys. Lab., Boston, Mass., 22-23 April 1991.

Taylor, M. J., and M. A. Hapgood, Identification of a thunderstorm as a source of short period gravity waves in the upper atmospheric nightglow emission, Planet. Space Sci., 36, 975-985, 1988.

Taylor, M. J., and M. A. Hapgood, On the origin of ripple-type wave structure in the nightglow emission, Planet. Space Sci., 38, $1421-$ 1430, 1990.

Taylor, M. J., M. A. Hapgood, and P. Rothwell, Observations of gravity wave propagation in the OI $(557.7 \mathrm{~nm}), \mathrm{Na}(589.2 \mathrm{~nm})$ and the nearinfrared $\mathrm{OH}$ nightglow emissions, Planet. Space Sci., 35, 413-427, 1987.

Taylor, M. J., E. H. Ryan, T. F. Tuan, and R. Edwards, Evidence of preferential directions for gravity wave propagation due to wind filtering in the middle atmosphere, J. Geophys. Res., 98, 6047-6057, 1993.

Walterscheid, R. L., J. H. Hecht, R. A. Vicent, I. M. Reid, J. Woithe, and M. P. Hickey, Analysis and interpretation of airglow and radar observations of quasi-monochromatic gravity waves in the upper mesosphere and lower thermosphere over Adelaide, Australia $\left(35^{\circ} \mathrm{S}, 138^{\circ} \mathrm{E}\right)$, J. Atmos. Sol. Terr. Phys., 61, 461-468, 1999.

Zhong, L., A. H. Manson, L. J. Sonmor, and C. E. Meek, Gravity wave exclusion circles in background flows modulated by the semi-diurnal tide, Ann. Geophys, 14(5), 557-565, May 1996.

P. P. Batista, D. Gobbi, and H. Takahashi, Instituto Nacional de Pesquisas Espaciais, Av. Dos Astronautas 1758-Cx. 515, São José dos Campos, SP, Brazil 12201-970. (pbatista@laser.inpe.br; Delano@laser.inpe.br; hisao@ laser.inpe.br)

A. F. Medeiros, Departamento de Física, Universidade Federal de Campina Grande (UFGC), Av. Aprígio Veloso 882, Bodocongó, Campina Grande, PB, Brazil 58109-970, Brazil. (afragoso@df.ufpb.br)

M. J. Taylor, Physics Department, Utah State University, Logan, Utah 84322-4405, USA. (michael.taylor@usu.edu) 